\title{
NUCLEAR ENERGY AND SECURITY
}

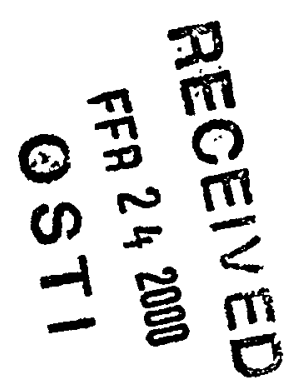

Thomas E. Blejwas, Thomas L. Sanders, Robert J. Eagan, and Arnold B. Baker

Sandia National Laboratories*

P.O. Box 5800

Albuquerque, NM 87185

\section{INTRODUCTION}

Nuclear power is an important and, we believe, essential component of a secure nuclear future. Although nuclear fuel cycles create materials that have some potential for use in nuclear weapons, with appropriate fuel cycles, nuclear power could reduce rather than increase real proliferation risk worldwide. Future fuel cycles could be designed to avoid plutonium production, generate minimal amounts of plutonium in proliferationresistant amounts or configurations, and/or transparently and efficiently consume plutonium already created. Furthermore, a strong and viable U.S. nuclear infrastructure, of which nuclear power is a large element, is essential if the U.S. is to maintain a leadership or even participatory role in defining the global nuclear infrastructure and controlling the proliferation of nuclear weapons.

By focusing on new fuel cycles and new reactor technologies, it is possible to advantageously burn and reduce nuclear materials that could be used for nuclear weapons rather than increase and/or dispose of these materials. Thus, we suggest that planners for a secure nuclear future use technology to design an "ideal" future. 'In this future, nuclear power creates large amounts of virtually atmospherically clean energy while significantly lowering the threat of proliferation through the thoughtful use, physical security, and agreed-upon transparency of nuclear materials. We must develop options for policy makers that bring us as close as practical to this ideal. Just as "Atoms for Peace" became the ideal for the first nuclear century, we see a potential nuclear future that contributes significantly to "power for peace and prosperity."

\section{THE NEED FOR NUCLEAR POWER}

Most of the arguments for nuclear power are well known to participants in this conference. Nuclear power does not generate carbon dioxide as a part of the fuel cycle 


\section{DISCLAIMER}

Portions of this document may be illegible in electronic image products. Images are produced from the best available original document. 


\section{DISCLAIMER}

This report was prepared as an account of work sponsored by an agency of the United States Government. Neither the United States Government nor any agency thereof, nor any of their employees, make any warranty, express or implied, or assumes any legal liability or responsibility for the accuracy, completeness, or usefuiness of any information, apparatus, product, or process disclosed, or represents that its use would not infringe privately owned rights. Reference herein to any specific commercial product, process, or service by trade name, trademark, manufacturer, or otherwise does not necessarily constitute or imply its endorsement, recommendation, or favoring by the United States Government or any agency thereof. The views and opinions of authors expressed herein do not necessarily state or reflect those of the United States Government or any agency thereof. 
(except for small amounts associated with mining and other operations); it uses a highly concentrated fuel that is relatively abundant in the U.S. (and with breeder reactors could supply power for centuries); and it has an outstanding safety record in the U.S. Numerous authors have made compelling arguments for the need for nuclear power in our future (see, for example, America the Powerless, Facing our Nuclear Energy Dilemma by Allen D. Waltar, which is both a very complete and very readable treatise).

In addition to reasoned analyses in articles and books that support the need for nuclear power, some analysts have created models and have used those models to show potential impacts and benefits from nuclear power by examining different scenarios (see, for example, Krakowski). These models are generally the basis for debate and discussion among "insiders" in the nuclear arena, but often are not exposed to or applied by decision-makers.

Recently at Sandia National Laboratories, teams led by Dr. Arnold Baker have developed a series of reduced form dynamic simulation models that integrate energy, economic and environmental aspects of complex systems, run on lap-top PCs, and allow the user to easily vary input parameters. One model, the USEGM, (a U.S. energy and greenhouse gas model developed by Arnold Baker, Thomas Drennen, Orman Paananen and David Harris) integrates U.S. energy markets and carbon emissions by energy use sector and fuel through 2020. It is a demand side model that is largely driven by income, prices and energy efficiency.

The first curve in Figure $1^{*}$ presents a base case from that model for U.S. carbon emissions. This case is benchmarked to the energy use and mix patterns in the DOE/EIA 1999 Annual Energy Outlook Reference Case through the year 2020. Note that emissions increase $48 \%$ from 1990 to 2020, while the goal of the Kyoto Protocol is a 7\% decrease by 2008-2012. The second curve in Figure 1 was generated by assuming that nuclear energy and renewables grow to $50 \%$ of electricity production in 2020 . This reduces carbon emissions in 2020 by $13 \%$ from the base case, but emissions would still grow substantially.

Figure 1. Base case (1) compared to scenario (2) with nuclear and renewables increased to $50 \%$ by 2020 .

*Figures are actual screen prints from the PC model. 


\section{CURBING CARBON EMISSIONS}

What would it take to significantly curb carbon emissions, while allowing continuing increases in energy consumption? In Figure 2, we assume again that the noncarbon electric share is increased to $50 \%$ (as in Figure 1) and, additionally, that $20 \%$ of transportation vehicles are electric by 2020 . Obviously, the improvements in emissions are small, but in the right direction.

Figure 2. Scenario (2) with $20 \%$ electric vehicles and $50 \%$ non-carbon-based electricity by 2020 compared to base case (1).

Figure 3. Scenario (2) with $100 \%$ of electricity generated by nuclear and renewables compared to base case (1) and Kyoto target. 
Based on our experience with the models, measures more drastic than can be imagined in twenty years are necessary. For example, in Figure 3, we show the results of replacing all coal, oil, and natural gas-fired generation of electricity with renewables and nuclear energy by 2010 . Such draconian measures would significantly reduce carbon emissions, but are clearly unrealistic. And even in this case, U.S. carbon emissions rise between 2010 and 2020 above the Kyoto target in response to U.S. economic growth.

To permit a fuller exploration of such issues, we are developing models that look further into the future and allow more complex relationships to be included. We expect these models to show that significant changes in transportation and manufacturing systems will be necessary, in addition to changes in the production of electricity. It is worth noting that rather than converting vehicles to battery-supplied electricity, we could have assumed that transportation systems convert to hydrogen as a fuel (e.g., hydrogen fuel cells) and the hydrogen is generated with nuclear power; but the model cannot presently accommodate this scenario. A Nuclear Energy Research Initiative (NERI) activity at Sandia National Laboratories, funded by the U. S. Department of Energy (DOE), is investigating nuclear generation of hydrogen.

\section{NUCLEAR MATERIALS MANAGEMENT}

The so-called once-through uranium fuel cycle mandated in the U.S. and common in much of the rest of the nuclear world results in spent fuel with significant amounts of plutonium and other actinides. Therefore, some would suggest (see, for example, Krakowski, et al.) that increasing the reliance on nuclear energy may reduce the potential for global warming but increases the amount of plutonium and, consequently, the proliferation risk. But should we assume that the amount of plutonium in spent fuel is directly proportional to proliferation risk? Are we forever tied to a once-through uranium fuel cycle? We believe that the answer to both questions must be a resounding no!

Unfortunately, our models cannot presently accommodate alternative fuel cycles, recycling, or other new technologies; but the possibilities are numerous. For example, Los Alamos National Laboratory has advocated the accelerator transmutation of waste (ATW) and Congress recently allocated $\$ 9 \mathrm{M}$ for research on advanced spent-fuel treatment, with emphasis on the ATW. General Atomic advocates the burning of plutonium using a graphite-moderated, gas-cooled, thermal-neutron reactor in conjunction with an accelerator. There is considerable attention, internationally, on the use of fast-neutron reactors for converting fertile material to fissile material, generating energy, and burning actinides. The burning of mixed oxide fuels (MOX) in conventional light-water reactors is one approach to consuming weapons plutonium, with the residual plutonium in hot spent fuel. Other schemes for more directly burning plutonium have been proposed and should be investigated further. Many have suggested a thorium fuel cycle that would take advantage of the worlds large thorium resources and, potentially, provide a fuel cycle that is more proliferation resistant than the once-through uranium cycle. The possibilities for the future are exciting. If we can develop clear paths forward, successfully inform policy makers, and perform appropriate research; the future can be more secure.

\section{GLOBAL NUCLEAR MATERIALS MANAGEMENT}

Global nuclear material management, started at Sandia National Laboratories as a visionary concept for tying the national security benefits of materials back to proliferation prevention, arms control and civilian nuclear power. Under the leadership of Senator 
Sam Nunn, the Center for Strategic and International Studies (CSIS) organized two workshops on GNMM. To quote results of the CSIS GNMM Policy Forum, July 1999:

"The vision of Global Nuclear Material Management (GNMM) is of a world in which all nuclear materials are safe, secure, and accounted for, from "cradle-tograve,"with sufficient transparency to assure the world that this is the case. That is a daunting goal, which must be approached step by step, within well-defined strategic framework. This panel has identified two key areas where the need for action is particularly urgent:

Eroding controls in the former Soviet Union. Insecure and oversized nuclear weapons and materials stockpiles in the former Soviet Union, with little transparency in their management, coupled with an oversized and underfunded nuclear complex, pose severe threats to U.S. and international security. The possibility that the essential ingredients of nuclear weapons could fall into the hands of terrorists and proliferating states is all too real, and immediate actions are needed to reduce this threat to the security of America and the world....

A withering foundation for U.S. leadership. Judged by any of a broad range of criteria, the infrastructure of U.S. leadership in nuclear technologies has greatly weakened over the last two decades. U.S. nuclear Research \& Development (R\&D) is dwarfed by $R \& D$ underway in other nations, the cadre of experienced personnel is dwindling, and nuclear engineering departments at U.S. universities are shrinking. The United States has virtually disengaged from international discussions and cooperation on the future of the nuclear fuel cycle. If the United States can no longer credibly claim a leadership role in nuclear technology, or is seen as having no interest in the future of nuclear energy, its ability to lead in nonproliferation could be substantially undermined."

Furthermore, the GNMM report recommends that "immediate action be taken to rebuild the $R \& D$ program, the cadre of experts, the $R \& D$ facilities, and material infrastructure that help provide the foundation for global leadership." Many of us at the DOE's weapons laboratories see GNMM as a companion effort to stockpile stewardship. Clearly, the future of nuclear energy must be integrated with the global management of nuclear materials.

\section{PUBLIC ATTITUDES TOWARDS THINGS NUCLEAR}

We have all heard that public attitudes will prevent a future reliance on new nuclear power systems. However, independent polling by Hank Jenkins-Smith at the University of New Mexico (some of which was sponsored by Sandia National Laboratories), found a somewhat different picture:

"First, Americans do not want to abandon nuclear energy. When a nationwide sample of Americans were asked whether the current utilization of nuclear energy in the United States should be decreased, kept the same, or increased, about $43 \%$ wanted to keep it the same and around $30 \%$ wanted to increase it. Approximately $27 \%$ wanted to decrease reliance on nuclear energy.

Second, most Americans would like the government to investigate prospects for reusing spent nuclear fuel rods, even when apprised of the possible proliferation risks associated with reprocessing. In fact, whether it is called "reusing" or "recycling" spent nuclear fuel, about 4 out of 5 respondents to a random sample of Americans were in favor of making use of spent fuel to produce more energy. . . . 
The point behind these examples is that Americans do see substantial benefits in the use of nuclear technologies, whether they be for energy or national security. But these benefits are not addressed in our fragmented nuclear policy discussion concerning nuclear waste management. When it comes to waste, regardless of who asks, most Americans are opposed to having waste shipped through their communities or disposed of in facilities in their states. Why is that?

A lot of our research has been focused on why people react as they do to the prospect of nuclear waste transport and storage. In a nutshell, when faced with a controversial problem like nuclear waste, Americans want to hear good and robust reasons for a policy. They want to see that the solution offered is a long term one. And they want to be able to identify tangible national benefits from the policy." We believe that an "ideal" nuclear future could have sufficient tangible national benefits for the American public to react positively.

\section{TOWARDS AN "IDEAL" NUCLEAR FUTURE}

Our view of an ideal nuclear future is one in which nuclear is well positioned to be a substantial contributor to the concept of "power for peace and prosperity." It includes the following: First, nuclear energy would be fully cost-competitive and plentiful and would contribute significantly to the avoidance of carbon emissions in our

atmosphere. Second, through a combination of advanced nuclear fuel cycles and nuclear technologies, amounts of fissile materials largely would be reduced to those necessary for energy production and limited nuclear weapons use. Nuclear weapons would not exist beyond the existing weapons states. Third, any fissile materials, whether separated or in spent fuel, would be safe, physically secure and transparent through the implementation of international agreements and participatory $R \& D$.

Reaching this future nuclear state is a daunting task. What is required? First, we have to create a vision of a sound, integrated, pragmatic nuclear future. Hopefully this paper will contribute to that vision in some small way. Technical approaches for achieving the vision must be developed. We believe that models that are extensions of the dynamic simulation models presented above could help define the range of possibilities. In the hands of experienced planners, such models could help define where advanced technologies could have the greatest impacts. By using such models to interact with policy-makers and their technical staff, more informed decisions about R\&D funding can be made. With the results of sound research and further advanced models, we will have prepared our future administrations and congresses to negotiate internationally and to put in place comprehensive energy, nuclear, and national security policies.

\section{A LEVEL PLAYING FIELD}

Creating an economic and/or environmental level playing field for nuclear power may be possible, but the aspects that nuclear shares with nuclear weapons can never be level with other fuel sources. A common misconception is that eliminating nuclear energy would help our proliferation problems by eliminating the generation of tons of plutonium-containing spent fuel. But as a practical matter, if the U.S. abandoned nuclear energy, the use of nuclear energy outside the U.S. still would continue, and the U.S. would weaken seriously its ability to deal with proliferation issues. The proliferation threat of U.S. spent nuclear fuel is insignificant compared to the real risk of loss of control of separated fissile materials in the former Soviet Union, for example. As noted in the GNMM report, another real threat is the loss of nuclear infrastructure and any kind 
of leadership position for things nuclear. Also, as noted above, future nuclear fuel cycles give the U.S. the potential to burn or otherwise reduce fissile materials. Therefore, we must find ways to help U.S. policy makers support development of an integrated U.S. nuclear policy, despite the complexity of the issue and the complexity of our political system. Such an integrated politically acceptable policy is the only way to achieve the potential energy, economic and environmental benefits from nuclear power and the protection from nuclear weapons and materials that the world demands.

\section{ACKNOWLEDGEMENT}

"Sandia is a multiporgram laboratory operated by Sandia Corporation, a Lockheed Martin Company, for the United States Department of Energy under Contract DE-AC0494AL85000."

\section{REFERENCES}

A.D. Waltar, America the Powerless, Facing Our Nuclear Energy Dilemma, Cogito Books, Madison, Wisconsin, 1995.

R.A. Krakowski, L. Bennett, and E. Bertel, "Nuclear Fission: For Safe, Globally Sustainable, Proliferation-Resistant, and Cost-Effective Energy," Proceedings of the International Conference on Preparing the Ground for Renewal of Nuclear Power, held October 22-23,1998, edited by B.N. Kursunoglu, et al., Kluwer Academic / Plenum Publishers, 1999.

Center for Strategic and International Studies, Global Nuclear Materials Management Policy Forum, July 1999, Sam Nunn, Chair.

H. Jenkins-Smith, Congressional Testimony, May 1998. 


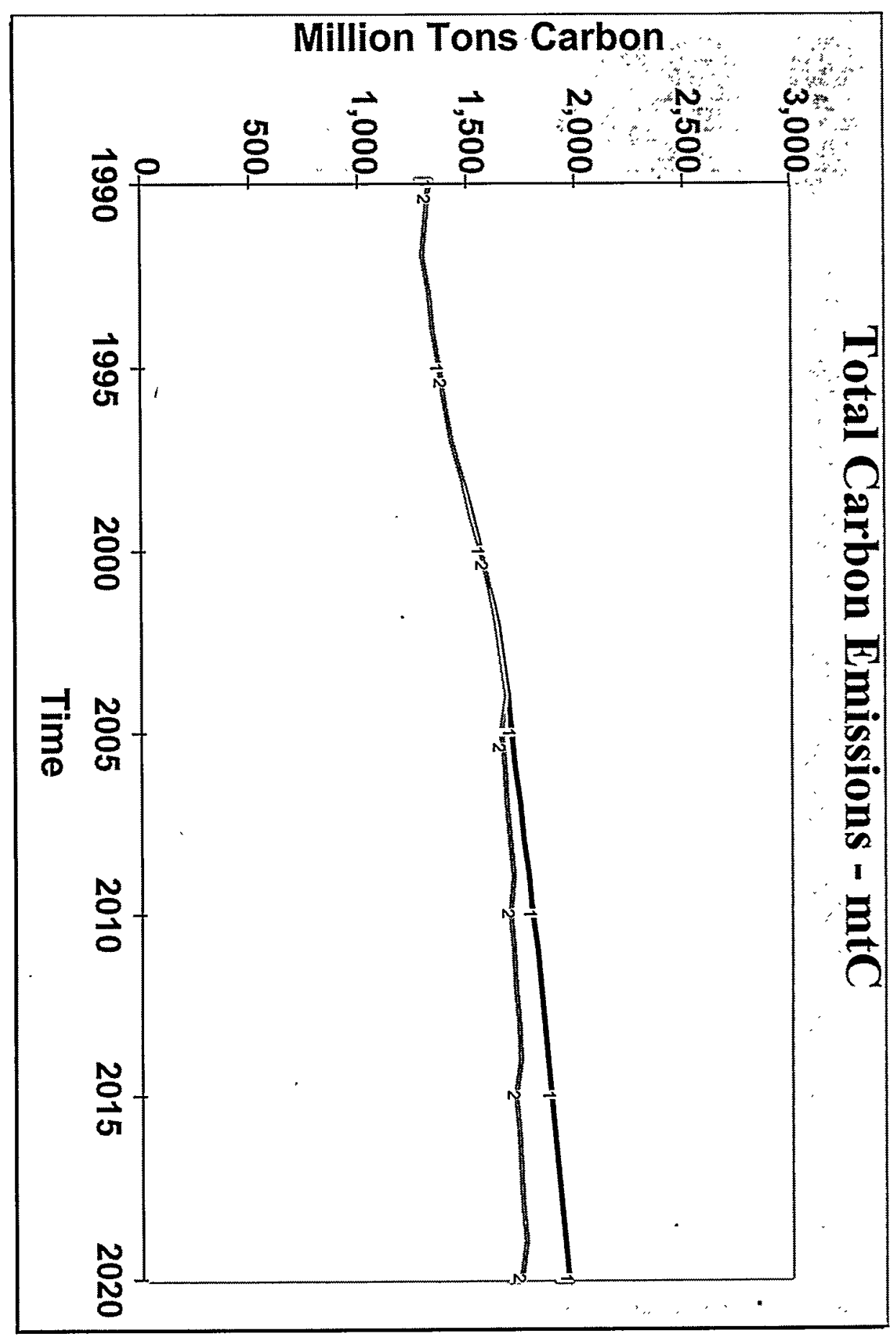

䍂 


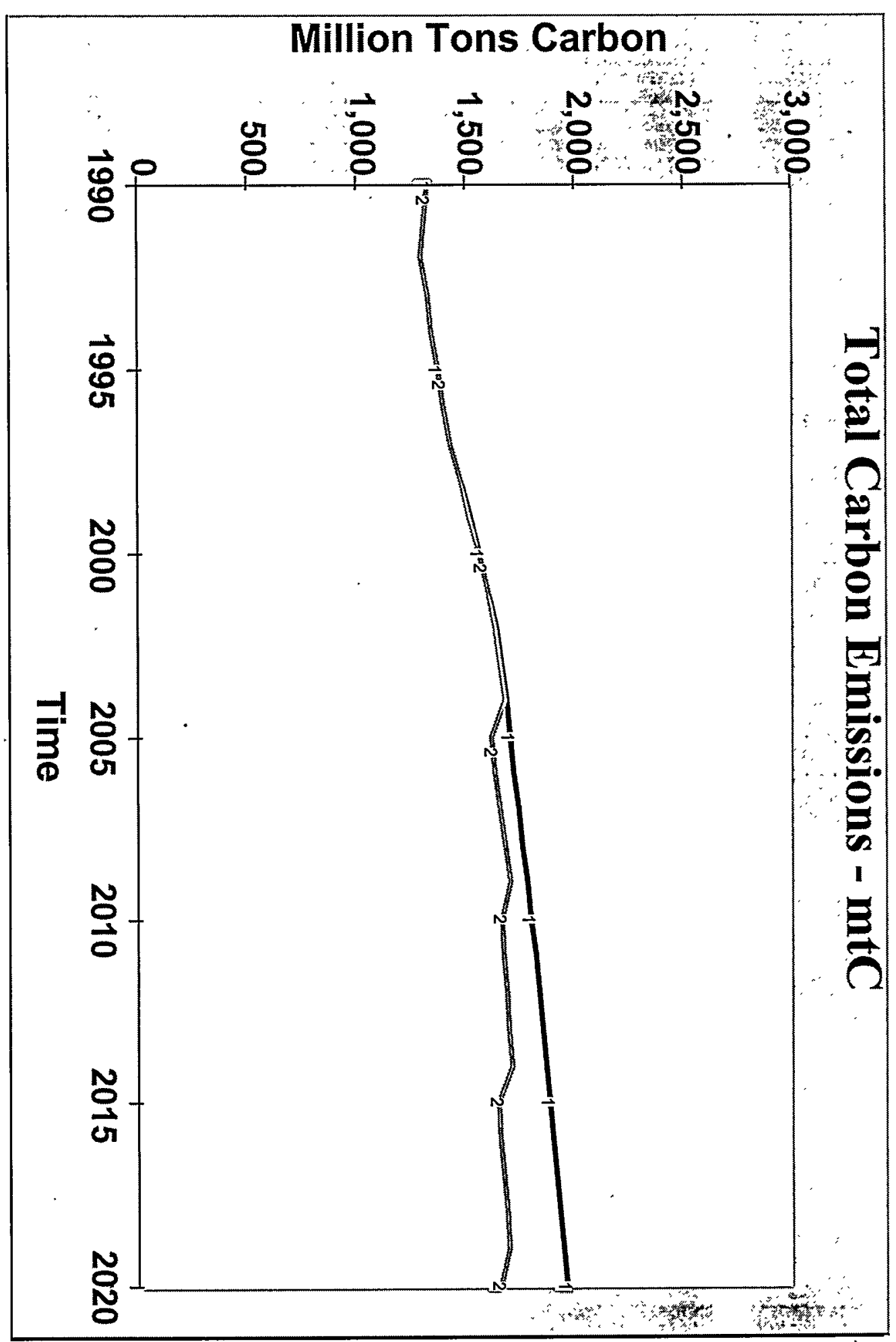




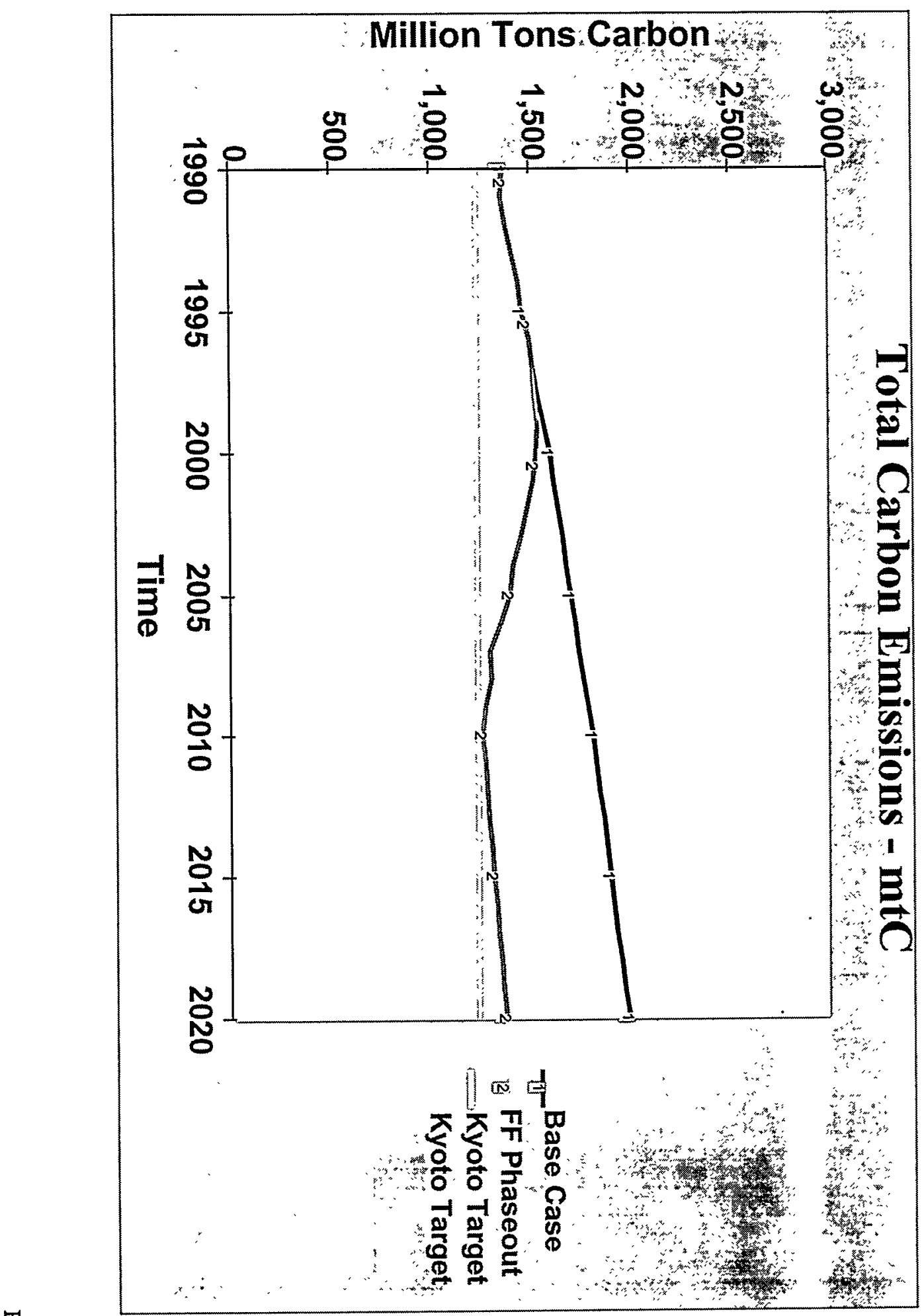

